Article

\title{
Synthesis of Polypyrrole/ $\mathrm{V}_{2} \mathrm{O}_{5}$ Composite Film on the Surface of Magnesium Using a Mild Vapor Phase Polymerization (VPP) Method for Corrosion Resistance
}

\author{
Jiawei Li, Yuan He, Yanan Sun, Xiuming Zhang, Wei Shi * and Dongtao Ge * \\ Key Laboratory of Biomedical Engineering of Fujian Province University/Research Center of Biomedical \\ Engineering of Xiamen, Department of Biomaterials, College of Materials, Xiamen University, \\ Xiamen 361005, China; imbiglee@163.com (J.L.); heyuan_1988@126.com (Y.H.); sunyanan@xmu.edu.cn (Y.S.); \\ zhangxiuming@xmu.edu.cn (X.Z.) \\ * Correspondence: shiwei@xmu.edu.cn (W.S.); gedt@xmu.edu.cn (D.G.)
}

Received: 5 March 2020; Accepted: 15 April 2020; Published: 18 April 2020

\begin{abstract}
The vapor phase polymerization (VPP) method is a conventional strategy for synthesizing conducting polymers (CPs) on the surfaces of various materials. However, the current VPP method performed on a metal surface usually requires harsh reaction conditions, such as high temperature and low vacuum. In this paper, a polypyrrole (PPy) and vanadium pentoxide $\left(\mathrm{V}_{2} \mathrm{O}_{5}\right)$ composite film was synthesized on the surface of $\mathrm{Mg}$ using a mild VPP method. Here, $\mathrm{V}_{2} \mathrm{O}_{5}$ was used as an oxidant, and it was found that the oxidation of pyrrole (Py) vapor on the surface of $\mathrm{V}_{2} \mathrm{O}_{5}$, which had been previously coated on the surface of $\mathrm{Mg}$, could be performed at room temperature under normal atmospheric pressure. The formation of the PPy $/ \mathrm{V}_{2} \mathrm{O}_{5}$ composite was verified by Fourier transform infrared spectroscopy (FTIR) and energy dispersive X-ray (EDX) spectroscopy. A thermogravimetric analyzer (TGA) was used to study the thermal stability of the composite. Subsequent corrosion tests showed that the PPy $/ \mathrm{V}_{2} \mathrm{O}_{5}$ composite film could slow down the corrosion of $\mathrm{Mg}$ in $3.5 \mathrm{wt} \% \mathrm{NaCl}$. It is expected that the mild VPP method may find great potential in the fields of synthesis of CPs and the corrosion protection of reactive metals.
\end{abstract}

Keywords: vapor phase polymerization; polypyrrole film; magnesium; corrosion protection; conducting polymers

\section{Introduction}

Metals are of industrial interest as structural material due to their high density and high strength to weight ratio. However, their poor corrosion resistance limits their applications. Metal anticorrosion is a process of inhibiting corrosion through physical and chemical means, which is of great significance for many aspects, such as industrial production and biomedical materials. In the last two decades, with the development of metal chemistry, alloying effects, and the electrochemical and polymer field, research has produced many options for the improvement of the corrosion resistance of metals, such as electrochemistry [1,2], chemical coatings [3], electroplating [4], and chemical oxidation anticorrosion [5]. Among them, coating technology is a very common method. Anticorrosive coatings include organic polymers [6], metal oxide [7], and graphene-containing composites [8]. Among them, conducting polymers (CPs) are one of the most important coating materials due to their electronic conductivity, optical transparency, and mechanical flexibility [9-12].

However, CPs, particularly those formed from unfunctionalized monomers, are often insoluble or require solvents which are unsafe and costly [13]. Therefore, chemical vapor deposition methods 
such as vapor phase polymerization (VPP) have been developed for the synthesis of CPs on a variety of substrate surfaces [14-17]. The main advantage of these methods is that they require no solvents. VPP is a two-step process. The first step is to precoat the oxidant onto the substrate, usually using a wet chemistry method. The second step is to expose the pretreated sample to monomer vapor in a vacuum chamber [18]. This technique is a useful deposition method for fabricating CPs because of its unique characteristics, including its solvent-free synthesis, uniformity of growth, mechanical flexible film, and industrial scale-up. However, the current VPP method performed on a metal surface usually requires harsh reaction conditions, such as high temperature and low vacuum, and conducting polymer anticorrosive coatings synthesized by the VPP method is mainly performed on the inert metal surface [19-21]. To the best of our knowledge, there are no reports on the synthesis of CPs on the surface of reactive metals (such as Mg) using the VPP method.

In this article, we report a mild VPP method for synthesizing CP polypyrrole (PPy) and vanadium pentoxide $\left(\mathrm{V}_{2} \mathrm{O}_{5}\right)$ composite films on the surface of reactive metal $\mathrm{Mg}$ at room temperature under normal atmospheric pressure. The morphology of PPy-based composite films was characterized by Fourier transform infrared spectroscopy (FTIR), a scanning electron microscope (SEM), and energy dispersive X-ray (EDX) spectroscopy. Nanowires with a diameter of about $50 \mathrm{~nm}$ were observed. Thermogravimetric analysis (TGA) was used to study the differences among products synthesized at different temperatures. The conductivity of composite films reached $1.22 \mathrm{~S} / \mathrm{cm}$. Eventually, we got acceptable corrosion resistance results from the $\mathrm{Mg}$ samples covered by the composite films through an electrochemical test.

\section{Materials and Methods}

\subsection{Test Materials}

Magnesium foil (99.99\%) was provided by Hui-Ye Magnesium Marketing Co., Ltd. (Shizuishan, China), which was cut into $15 \mathrm{~mm} \times 15 \mathrm{~mm}$ pieces. The sample of $\mathrm{Mg}$ foil was polished by silicon carbide papers (800-2000 mesh), cleaned in ethanol for 10 min within the ultrasonic bath; after that, the $\mathrm{Mg}$ foil was dried in warm air. Pyrrole (Py) was purchased from Sinopharm Chemical Reagent Co., Ltd. (Shanghai, China), distilled under the protection nitrogen gas, and stored in $-20^{\circ} \mathrm{C} . \mathrm{V}_{2} \mathrm{O}_{5}$ hydrogel having a solid content of 1.2 to $1.8 \mathrm{wt} \%$ as reported in the literature [22] was used, and other solvents and reagents were analytically pure level and purchased from Sinopharm Chemical Reagent Co., Ltd. (Shanghai, China).

\subsection{Synthesis of $\mathrm{PPy} / \mathrm{V}_{2} \mathrm{O}_{5}$ Film on the Surface of $\mathrm{Mg}$}

The preparation of PPy $/ \mathrm{V}_{2} \mathrm{O}_{5}$ nanostructures on $\mathrm{Mg}$ foil was carried out at room temperature in a sealed wide-mouth bottle. The exposed area of $\mathrm{Mg}$ is $15 \mathrm{~mm} \times 15 \mathrm{~mm}$. Before transferring the sample, we added a Py monomer into the bottle and kept it sealed for $30 \mathrm{~min}$ for forming Py vapor pressure. The $\mathrm{V}_{2} \mathrm{O}_{5}$ hydrogel-coated $\mathrm{Mg}$ foil was immediately put into the prepared Py atmosphere. After $12 \mathrm{~h}$ of polymerization reaction, the $\mathrm{Mg}$ foil was taken out and dried at room temperature.

\subsection{Performance Test}

Surface morphological characteristics of all samples were observed by a field emission scanning electron microscope (SEM, SU-70, Hitachi, Tokyo, Japan). The element composition analysis was performed using an energy dispersive X-ray detector (EDX, SU-70, Hitachi, Tokyo, Japan). The composition of the film was characterized by attenuated total reflection-Fourier transform infrared reflection (FTIR, is10, Nicolet, Madison, WI, USA) spectroscopy. The thickness of the deposited film sample was detected by a step height profiler (ST, ET150, Kosaka, Tokyo, Japan). The measured samples were PPy $/ \mathrm{V}_{2} \mathrm{O}_{5}$ composites on $\mathrm{Mg}$ substrates $(15 \mathrm{~mm} \times 15 \mathrm{~mm})$. The conductivity is calculated after a two-step experiment. In the first step, the multi position film thickness of five samples was measured by an ET150 step meter (Kosaka, Tokyo, Japan). The path length was $500 \mu \mathrm{m}$, and different positions 
were selected for measurement. The final thickness of one sample was the average of all data. In the second step, the resistances of the five samples were measured by an RTS-9 four-probe conductivity tester (4PT, RTS-9, 4PROBES TECH, Guangzhou, China), and the resistances were measured at different points. Four orders of magnitude of a two-way voltage of $0.01,0.10,1.00$, and $10.0 \mathrm{mV}$ were applied. Thermogravimetric analysis (TGA) was carried out on the SDT Q600 thermogravimetric analyzer (TA Instruments, New Castle, DE, USA) with a heating rate of $20^{\circ} \mathrm{C} / \mathrm{min}$ in the oxygen condition. The electrochemical impedance spectrum (EIS) was carried out in a $3.5 \mathrm{wt} \% \mathrm{NaCl}$ solution at $25{ }^{\circ} \mathrm{C}$ with an Autolab-Nova electrochemical workstation (PGSTAT 302 N, Metrohm Autolab, Utrecht, Netherlands) using a $5 \mathrm{mV}$ alternating current (AC) sinusoid signal at a frequency range from $1000 \mathrm{kHz}$ to $0.1 \mathrm{~Hz}$. All electrochemical experiments were performed using a conventional three-electrode system at room temperature.

\section{Results and Discussion}

\subsection{Reaction Process}

The process of preparing PPy on the Mg surface by the VPP method is shown in Figure 1. The reaction steps are as follows: Firstly, $20 \mu \mathrm{L}$ of a Py monomer is added dropwise into a wide-mouth bottle with a ground glass stopper, in which a cylindrical Teflon block was placed. Because the vapor pressure of the Py monomer is 12.2 Torr at $25^{\circ} \mathrm{C}$ (for comparison, the vapor pressure of 3,4-ethoxylenedioxythiophene (EDOT) is 0.278 Torr at $25^{\circ} \mathrm{C}$ ) [18], it is beneficial to form a saturated vapor pressure in a closed space. Secondly, $65 \mu \mathrm{L}$ of $\mathrm{V}_{2} \mathrm{O}_{5}$ hydrogel is uniformly coated on the pretreated substrate, and then the $\mathrm{V}_{2} \mathrm{O}_{5}$-coated $\mathrm{Mg}$ is transferred promptly into the bottle, placed on the surface of the Teflon block. $\mathrm{V}_{2} \mathrm{O}_{5}$, which is the oxidant in the reaction, can oxidize the Py vapor into PPy, thereby obtaining a PPy/ $\mathrm{V}_{2} \mathrm{O}_{5}$ composite film on the $\mathrm{Mg}$ surface. All the above steps are performed at normal temperature and in a vacuum. After $12 \mathrm{~h}$, the sample is taken out from the bottle, washed, and dried at room temperature.

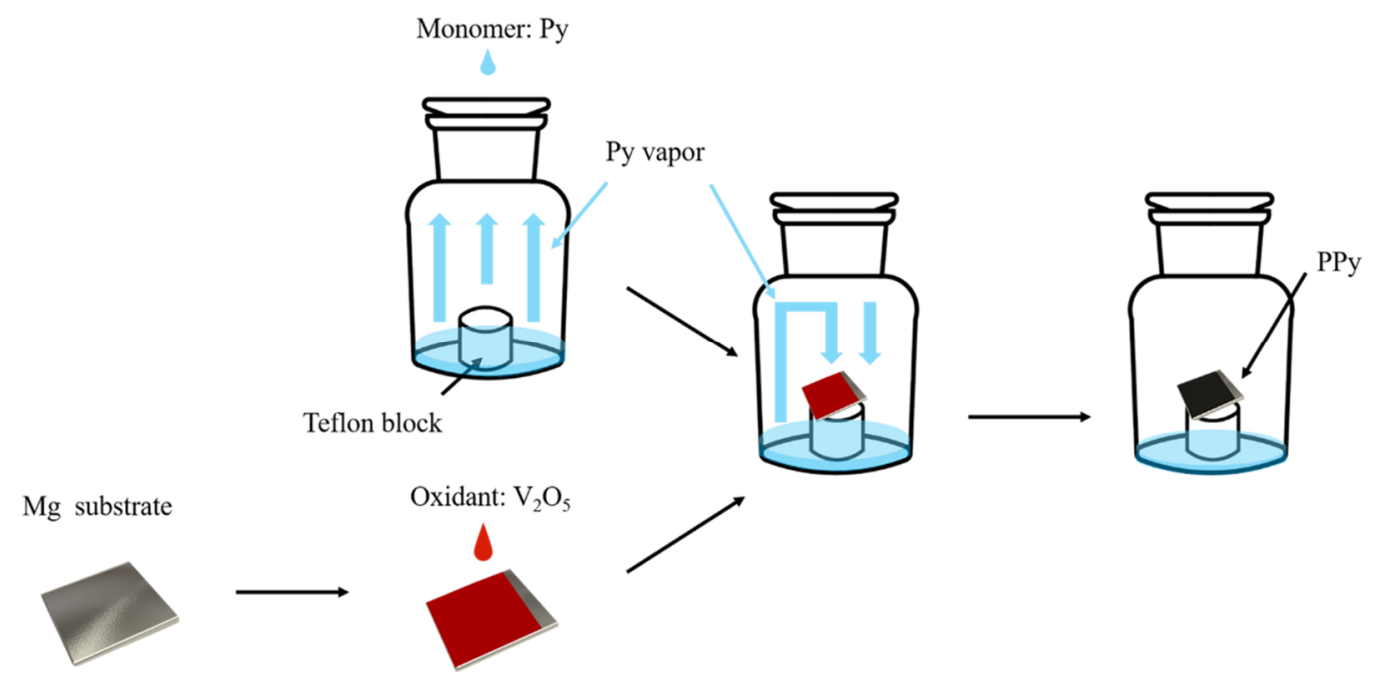

Figure 1. Schematic diagram for the synthesis of the polypyrrole (PPy)/vanadium pentoxide $\left(\mathrm{V}_{2} \mathrm{O}_{5}\right)$ composite film on the Mg surface by the mild vapor phase polymerization (VPP) method.

\subsection{Morphologies of the $\mathrm{PPy} / \mathrm{V}_{2} \mathrm{O}_{5}$ Film on the $\mathrm{Mg}$}

Figure 2a is the SEM image of $\mathrm{V}_{2} \mathrm{O}_{5}$ on the surface of $\mathrm{Mg}$. Nanowire morphology can be observed. Figure $2 \mathrm{~b}$ shows the morphologies of the PPy film. It can be seen clearly that after VPP, the surface of Mg was covered with the deposited PPy. The color quickly changed from dark red to black, which means Py polymerizes into PPy film on the surface of $\mathrm{Mg}$. Figure $2 \mathrm{c}$ is the digital photo of the sample in Figure $2 \mathrm{~b}$. The EDX of nanowires formed on the surface of $\mathrm{Mg}$ is shown in Figure $2 \mathrm{~d}$. In the 
spectrogram, the vanadium element was derived from the oxidant $\mathrm{V}_{2} \mathrm{O}_{5}$, the carbon elements were derived from PPy, and the magnesium was derived from the substrate. The oxygen element was observed, which is widely present in PPy and $\mathrm{V}_{2} \mathrm{O}_{5}$. It is concluded from the SEM and the EDX spectrogram that composite nanowires of PPy and $\mathrm{V}_{2} \mathrm{O}_{5}$ have been successfully synthesized on the surface of $\mathrm{Mg}$ foil with a diameter of about $50 \mathrm{~nm}$.
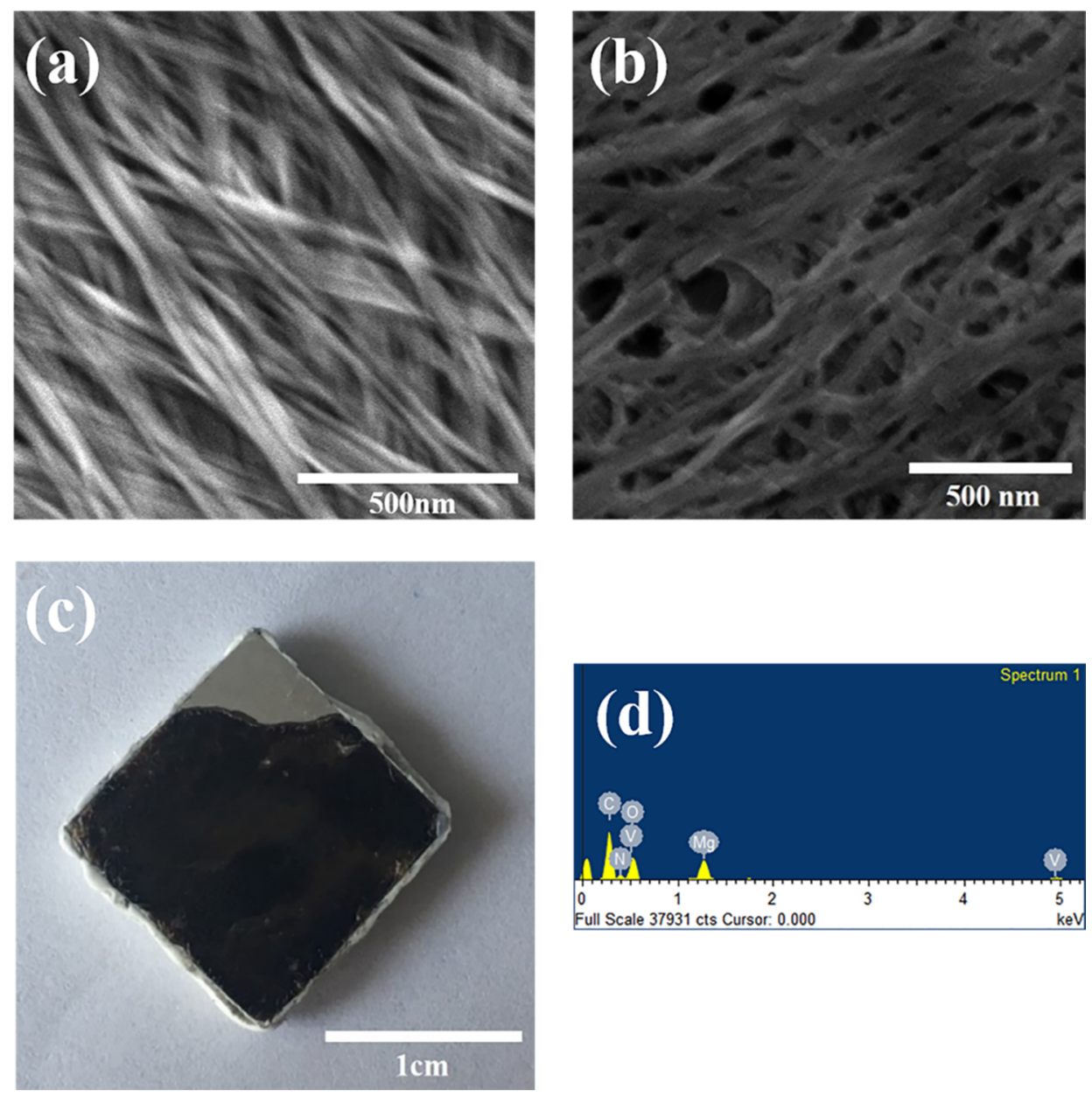

Figure 2. (a) SEM images of $\mathrm{V}_{2} \mathrm{O}_{5}$ nanowires on the $\mathrm{Mg}$; (b) Image showing that the synthesized nanowires are nearly $50 \mathrm{~nm}$ in diameter; (c) The dried sample film was black, indicating that the PPy was successfully synthesized; (d) The energy dispersive X-ray (EDX) of the composite of PPy/ $\mathrm{V}_{2} \mathrm{O}_{5}$ on the $\mathrm{Mg}$.

\subsection{FTIR Spectroscopic Analysis}

The FTIR spectrum of $\mathrm{V}_{2} \mathrm{O}_{5}$ and the PPy $/ \mathrm{V}_{2} \mathrm{O}_{5}$ composite are shown in Figure 3a. The red curve shows the FTIR spectrum of $\mathrm{V}_{2} \mathrm{O}_{5}$ with absorption bands at 971,837 , and $554 \mathrm{~cm}^{-1}$. The band at $971 \mathrm{~cm}^{-1}$ is due to $\mathrm{V}=\mathrm{O}$ stretching $[23,24]$. Bands at 837 and $554 \mathrm{~cm}^{-1}$ are assigned to $\mathrm{V}-\mathrm{O}-\mathrm{V}$ deformation modes [24,25]. $\mathrm{V}_{2} \mathrm{O}_{5}$ is transition metal oxide, and the vibration of vanadium oxygen group is concentrated in the range of $400-1000 \mathrm{~cm}^{-1}$. The band $1500 \mathrm{~cm}^{-1}$ is mostly caused by residual water molecules in the early stage of reaction, which is not $\mathrm{V}_{2} \mathrm{O}_{5}$ 's own characteristic peak. 

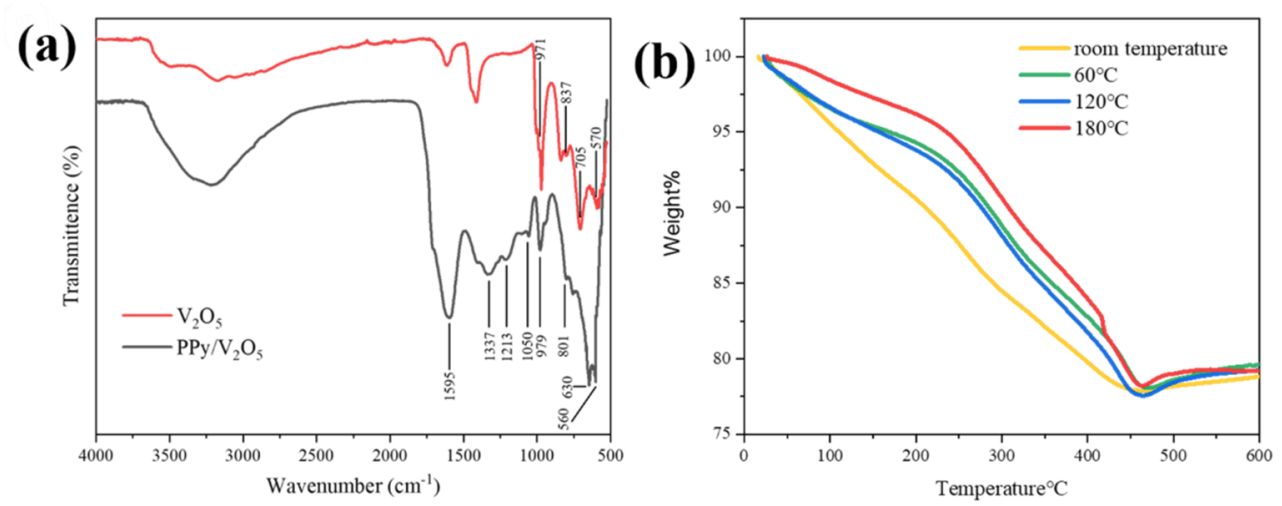

Figure 3. (a) FTIR spectra of $\mathrm{V}_{2} \mathrm{O}_{5}$ and PPy/ $/ \mathrm{V}_{2} \mathrm{O}_{5}$ composites. (b) TGA curves of PPy $/ \mathrm{V}_{2} \mathrm{O}_{5}$ composites synthesized at different temperatures.

Bands at $705 \mathrm{~cm}^{-1}$ are assigned to the $\mathrm{V}-\mathrm{OH}_{2}$ stretching mode due to the $\mathrm{H}_{2} \mathrm{O}$ in the structure [24]. The FTIR spectrum also shows the characteristic peaks of PPy $/ \mathrm{V}_{2} \mathrm{O}_{5}$ composites. The band at around $1595 \mathrm{~cm}^{-1}$ is allocated to a stretching vibration of $\mathrm{C}=\mathrm{C}$ in the Py ring [23-26]. The absorption band at $1337 \mathrm{~cm}^{-1}$ is related to $\mathrm{C}-\mathrm{H}$ in plane deformation modes [23-26]. The characteristic absorption bands at 1213 and $1050 \mathrm{~cm}^{-1}$ are due to the stretching vibrations of C-N and C-H of PPy, respectively [23]. The peak at $979 \mathrm{~cm}^{-1}$ is due to the $=\mathrm{CH}$ out of plane vibration. Bands at $801 \mathrm{~cm}^{-1}$ are due to the stretching vibration of $\mathrm{V}=\mathrm{O}$ in the remaining $\mathrm{V}_{2} \mathrm{O}_{5}$ in the composite product. The peak of $560 \mathrm{~cm}^{-1}$ is due to the vanadate ion bond in the composites [27]. The SEM and EDX experiments confirmed that the synthesized product is a composite containing PPy and $\mathrm{V}_{2} \mathrm{O}_{5}$.

\subsection{Thermogravimetric Analysis}

The thermal stability of the $\mathrm{PPy} / \mathrm{V}_{2} \mathrm{O}_{5}$ composite was studied via thermogravimetric analysis (TGA). Figure $3 \mathrm{~b}$ shows four thermogravimetric curves of film synthesizing at different temperatures (room temperature, 60, 120, and $180^{\circ} \mathrm{C}$ ). The test was performed from room temperature to $600{ }^{\circ} \mathrm{C}$. From the curves, three distinct temperature changes can be observed. The weight loss of about $5.0 \%-10.0 \%$ before $220^{\circ} \mathrm{C}$ in the curves is due to the release of adsorbed water, crystallization water, and residual intercalated water molecules in the $\mathrm{V}_{2} \mathrm{O}_{5}$ interlayer [28]. The second stage, which starts at $220{ }^{\circ} \mathrm{C}$ and ends at $450{ }^{\circ} \mathrm{C}$, is the main part of weight loss, indicating that the PPy in the $\mathrm{PPy} / \mathrm{V}_{2} \mathrm{O}_{5}$ composites begins to decompose, and the PPy long chain collapses. After $450{ }^{\circ} \mathrm{C}$, the weight of the sample grew about $2 \%$. Since the reduced product of $\mathrm{V}_{2} \mathrm{O}_{5}$ is vanadate ion, vanadate may be oxidized to higher valence and higher weight in oxygen at high temperature. In general, the thermogravimetric experiments show that the PPy content of the composites obtained by VPP at different temperatures is similar. The weight loss proceeded quite steadily, with a residue of about $78 \%$ at $450{ }^{\circ} \mathrm{C}$.

\subsection{Conductivity}

The conductivity is calculated by the following two-step experiments; our PPy $/ \mathrm{V}_{2} \mathrm{O}_{5}$-covered $\mathrm{Mg}$ substrates $(15 \mathrm{~mm} \times 15 \mathrm{~mm})$ are the same as the electrochemical test sample substrates. In the first step, after many times of measurement, the thickness data were concentrated at a value of $20-40 \mu \mathrm{m}$, so the film thicknesses of 20, 30 and $40 \mu \mathrm{m}$ were taken. In the second step, the resistances of five samples in the same batch were measured by a RTS-9 four-probe tester (Guangzhou four probe technology Co. Ltd., Guangzhou, China). After the electrical conductivity was obtained from the resistivity, the average value was calculated: For the thickness of $20 \mu \mathrm{m}$, the conductivity range of all samples is $0.39 \sim 1.22 \mathrm{~S} / \mathrm{cm}$; for the thickness of $30 \mu \mathrm{m}$, the conductivity range of all samples is $0.26 \sim 0.82 \mathrm{~S} / \mathrm{cm}$; for the thickness of $40 \mu \mathrm{m}$, the conductivity range of all samples is $0.20-0.24 \mathrm{~S} / \mathrm{cm}$ (Figure 4). 


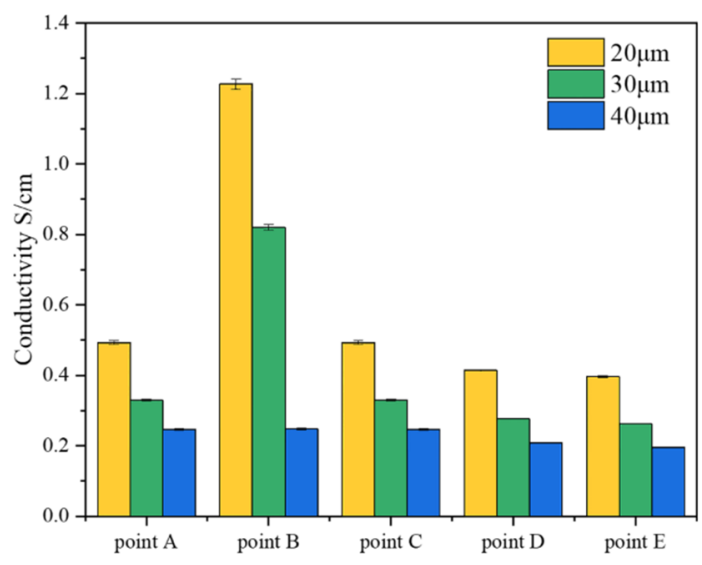

Figure 4. Conductivity of thin film.

Kim [29] prepared a composite film of polymethyl methacrylate (PMMA)/PPy by spin coating. The composite film can passivate the iron substrate through oxidation-reduction chemistry to provide corrosion protection. The electrical conductivity of the composite material is in the range of $0.30-1.84 \mathrm{~S} / \mathrm{cm}^{-1}$.

Jadhav [27] reported a PPy coating doped with vanadate and tungstate. With the degradation of PPy in the composite coating, the doped anions were released along with it, becoming a corrosion inhibitor in the system and slowing the corrosion of the aluminum substrate. The conductivity of PPy composite reached $0.05 \mathrm{~S} / \mathrm{cm}^{-1}$.

Feng Li [30] pointed out that the copolymer coating doped with sodium molybdate (PPy-PAnimolybdate) can promote the formation of passivation film on stainless steel substrate; we believe that PPy doped with vanadate anions has a similar effect.

Generally, the conductivity of $\mathrm{Mg}$ is $22 \times 10^{6} \mathrm{~S} \cdot \mathrm{m}^{-1}$. If the measured resistivity is a parallel resistance, the resulting parallel resistivity should be less than that of pure $\mathrm{Mg}$, and the resulting conductivity should be much greater than $22 \times 10^{6} \mathrm{~S} \cdot \mathrm{m}^{-1}$. However, the results prove that the obtained conductivity is similar to the reported $\mathrm{PPy} / \mathrm{V}_{2} \mathrm{O}_{5}$ conductivity, and it has not increased sharply, so what we measured is the conductivity of the composites. Meanwhile, the results prove that the conductivity of the final product $\mathrm{PPy} / \mathrm{V}_{2} \mathrm{O}_{5}\left(0.20-1.22 \mathrm{~S} / \mathrm{cm}^{-1}\right)$ is higher than the $\mathrm{V}_{2} \mathrm{O}_{5}$ conductivity $\left(0.05 \mathrm{~S} / \mathrm{cm}^{-1}\right)$ prepared by the same method [22], which is attributed to the PPy being doped.

\subsection{Characterization of the Corrosion Resistance}

\subsubsection{Tracing Quasistationary Polarization}

Corrosion tests of the nanostructured PPy $/ \mathrm{V}_{2} \mathrm{O}_{5}$ composite were investigated in order to evaluate its ability for regulating the degrade rate of $\mathrm{Mg}$. Figure 5 shows the polarization curves of the bare $\mathrm{Mg}$, $\mathrm{V}_{2} \mathrm{O}_{5}$-coated $\mathrm{Mg}$, and $\mathrm{PPy} / \mathrm{V}_{2} \mathrm{O}_{5}$-coated $\mathrm{Mg}$ foils soaking in $3.5 \mathrm{wt} \%$ sodium $\mathrm{NaCl}$ for $6 \mathrm{~h}$.

Compared to bare $\mathrm{Mg}$ and $\mathrm{V}_{2} \mathrm{O}_{5}$-coated $\mathrm{Mg}$, the Tafel plots of the PPy $/ \mathrm{V}_{2} \mathrm{O}_{5}$-coated sample gave a much more positive corrosion potential (Ecorr) and a lower corrosion current (Icorr). The Tafel extrapolations revealed that the presence of $\mathrm{PPy} / \mathrm{V}_{2} \mathrm{O}_{5}$ film caused a positive shift in the corrosion potential compared to the bare $\mathrm{Mg}$ and $\mathrm{V}_{2} \mathrm{O}_{5}$-coated $\mathrm{Mg}$ foil, indicating that the anticorrosion performance of $\mathrm{Mg}$ has been improved by the PPy deposits. By contrast, the anticorrosion ability of the $\mathrm{V}_{2} \mathrm{O}_{5}$-coated sample was only slightly better than that of bare $\mathrm{Mg}$. 


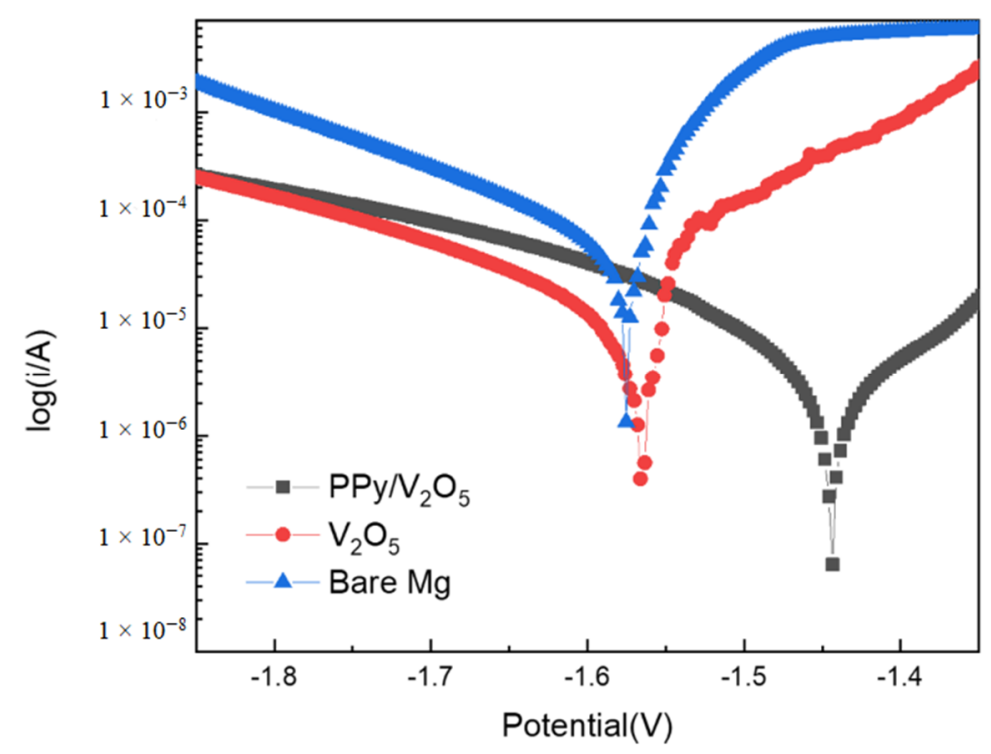

Figure 5. Tafel curves of bare $\mathrm{Mg}, \mathrm{V}_{2} \mathrm{O}_{5} / \mathrm{Mg}$ and $\mathrm{PPy} / \mathrm{V}_{2} \mathrm{O}_{5} / \mathrm{Mg}$.

\subsubsection{Electrochemical Impedance Spectroscopy}

Since $\mathrm{Mg}$ is very sensitive, electrochemical impedance spectroscopy (EIS) is also carried out to characterize the corrosion resistance of different samples from 0.5 to $96 \mathrm{~h}$ in a $3.5 \mathrm{wt} \% \mathrm{NaCl}$ solution (Figure 6). In general, the negative peak in the Bode-phase plots indicates the electrical conductivity between the films and the substrate. Meanwhile, the positive peak in the plots represents the unique inductive response of $\mathrm{Mg}$. In addition, a high corrosion-resistant system should have a slow decreasing resistance. Based on the changes of these EIS parameters, the corrosion damage of a film system can be estimated [31]. Figure 6a shows that the bare $\mathrm{Mg}$ has two positive peaks (upward) at the intermediate frequency region (10-104 Hz). In the Bode-impedance plot (Figure $6 \mathrm{~d}$ ), we find the impedance at $0.1 \mathrm{~Hz}$ of bare $\mathrm{Mg}$ experiences a fluctuation process. This phenomenon means that the passivation film is gradually destroyed in the $\mathrm{NaCl}$ solution, and $\mathrm{Cl}^{-}$invades the $\mathrm{Mg}$ substrate; pitting is getting worse after $24 \mathrm{~h}$.

Figure $6 \mathrm{~b}$ shows the samples covering $\mathrm{V}_{2} \mathrm{O}_{5}$, where the two positive peaks in the intermediate frequency region gradually divide into three positive peaks from 0.5 to $96 \mathrm{~h}$. The third peak appeared at $72 \mathrm{~h}$. The presence of such conductive behavior in the intermediate region suggests that the film has corrosion protection for the substrate. As time prolonged (after $72 \mathrm{~h}$ ), the position of the positive peak changed, indicating the degradation of the film and new chemical reaction. A similar Bode-phase plots characteristic was found in the $\mathrm{PPy} / \mathrm{V}_{2} \mathrm{O}_{5}$ composite film sample. The impedance of the composite film is higher and more stable than those of the previous two samples (bare $\mathrm{Mg}$ and $\mathrm{V}_{2} \mathrm{O}_{5}$ ). This conductive behavior indicates an improved anticorrosion protection from the PPy film. All results show that the $\mathrm{PPy} / \mathrm{V}_{2} \mathrm{O}_{5}$ composite film possesses the best anticorrosion ability. 
(a)

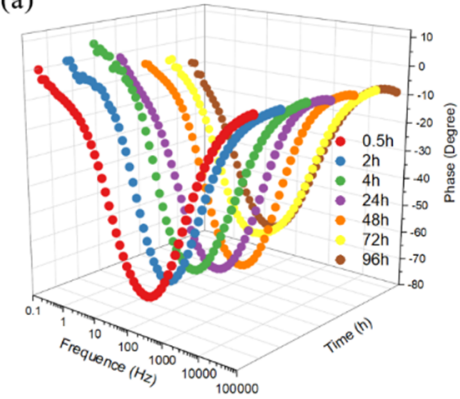

(d)

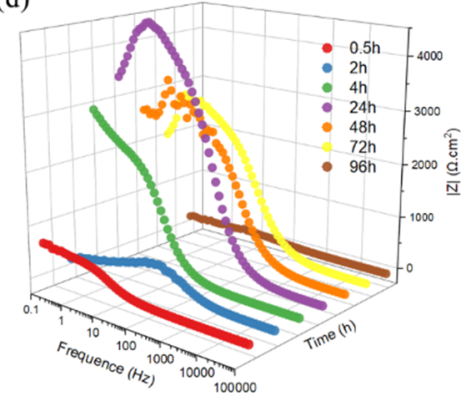

(b)

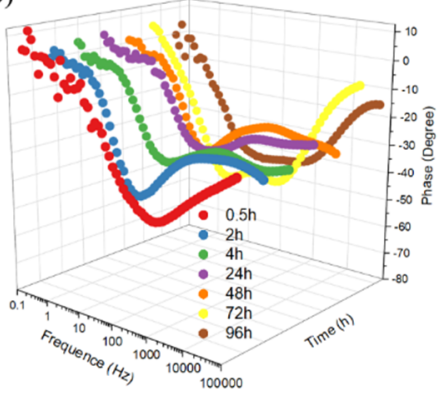

(e)

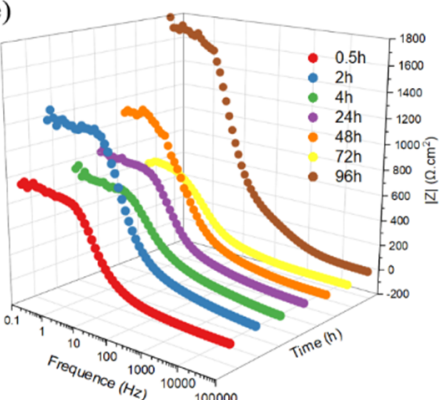

(c)

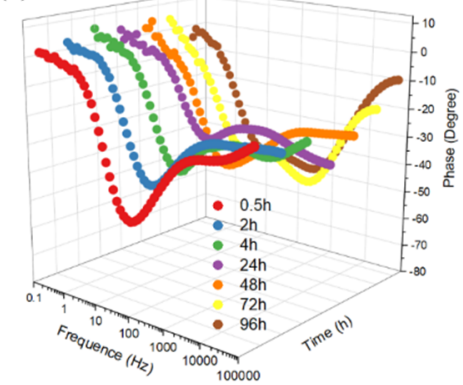

(f)

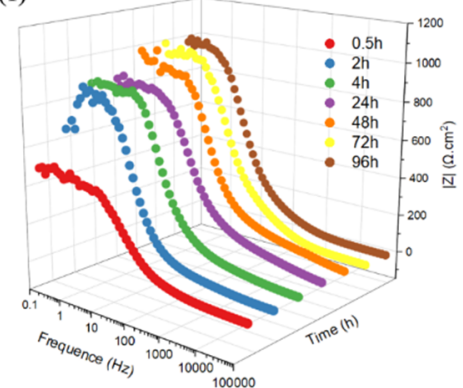

Figure 6. (a,d) Bode-phase and Bode-impedance plots of bare $\mathrm{Mg},(\mathbf{b}, \mathbf{e})$ Bode-phase and Bode-impedance plots of $\mathrm{V}_{2} \mathrm{O}_{5} / \mathrm{Mg}$, and (c,f) Bode-phase and Bode-impedance plots of PPy/ $\mathrm{V}_{2} \mathrm{O}_{5} / \mathrm{Mg}$.

\subsection{Mechanism of the Corrosion Resistance}

At present, there are many explanations for the mechanism of metal corrosion protection by PPy, but there is no final conclusion in the academic field. The main mechanisms include the anodic protection theory, controlled inhibitor release mechanism, conductive mechanism, etc. As for the composite film deposited by our VPP method, its corrosion protection can be explained in two periods.

In the first stage (before $24 \mathrm{~h}$ ), the physical barrier effect is dominant. Actually, the film of the nanowires has a large specific surface area and cannot be absolutely pinhole-free, but the coating thickness ranges from 20 to $40 \mu \mathrm{m}$, which is enough for the physical barrier effect to provide limited corrosion protection in a short period. In the second stage (after $24 \mathrm{~h}$ ), the conductive mechanism and anodic protection are dominant. On the one hand, because the Mg's reduction potential $(-2.37 \mathrm{~V})$ is lower than PPy's (-0.1-+0.3 V), the surface of Mg will react with PPy to form a passivation layer (a mixture of $\mathrm{Mg}$ hydroxide and oxide), which increases the overall potential. In addition, the $\mathrm{PPy} / \mathrm{V}_{2} \mathrm{O}_{5}$ composite film and the $\mathrm{Mg}$ substrate can be regarded as a whole due to their conductivity. When $\mathrm{Mg}$ loses electrons, it does not gather in the defect area; it can be transferred to other parts, which slows down the occurrence of pitting and corrosion.

We acknowledge that there is still a gap between the present VPP method and commercial anticorrosion methods, but it can be used as a new idea for corrosion protection. $\mathrm{Mg}$ is a promising biodegradable metal and has important application prospects in the biomedical field. However, its corrosion resistance is quite poor, which leads to rapid degradation within the human body and thus greatly limits the application in vivo. Therefore, it is of both great scientific and technical significance to slow down the degradation rate of $\mathrm{Mg}$. The use of PPy as a coating material can provide an effective way to meet this requirement.

\subsection{The Role of $\mathrm{V}_{2} \mathrm{O}_{5}$}

$\mathrm{V}_{2} \mathrm{O}_{5}$ plays the role of an oxidant and a template in our VPP method, and vanadate anion as the reduction product of $\mathrm{V}_{2} \mathrm{O}_{5}$ is a dopant for the composite. The specific reasons we chose $\mathrm{V}_{2} \mathrm{O}_{5}$ are as follows. First, the film formation of PPy is greatly affected by $\mathrm{V}_{2} \mathrm{O}_{5}$ hydrosol. If the storage time and the storage temperature are appropriate, the final nanostructure morphology will be complete. 
Second, unlike other oxidants (such as Fe (III) sulfonates) in VPP, $\mathrm{V}_{2} \mathrm{O}_{5}$ does not need to be heated to crystallization and thus without the requirement of high temperature and low vacuum because it can maintain excellent oxidizability under normal temperature and pressure. Third, after the polymerization of $\mathrm{Py}$, the $\mathrm{V}_{2} \mathrm{O}_{5}$ was reduced to vanadate ion, which exists in the composites as dopant.

\subsection{The Limitations of Our VPP}

PPy exposed to atmospheric conditions will gradually degrade. Our VPP method deposited PPy on $\mathrm{V}_{2} \mathrm{O}_{5}$ nanowires, so there is also the possibility of degradation. There are two factors that have a great influence on the degradation of VPP: (1) exposure to air, as the reaction of the PPy main chain with oxygen in the air leads to irreversible loss of conjugated structure; and (2) the loose porous structure leads to PPy adsorbing water in the air, leading to a reversible or partially reversible hydrolysis of a conjugated structure. If the next step is to carry out in-depth research on the application of metal anti-corrosion, these two points must be given attention.

$\mathrm{V}_{2} \mathrm{O}_{5}$ could remain in the reaction product. Whether $\mathrm{V}_{2} \mathrm{O}_{5}$ is present in the final product depends on the amount of pyrrole (Py) and the reaction time. If the amount of Py is excessive and time is long enough, $\mathrm{V}_{2} \mathrm{O}_{5}$ will be completely reacted, and there will be no residue in the product. If the amount of pyrrole is insufficient or the reaction time is short, a part of $\mathrm{V}_{2} \mathrm{O}_{5}$ will remain in the final product. If $\mathrm{V}_{2} \mathrm{O}_{5}$ is not removed by acid, there could be potential safety hazards.

\section{Conclusions}

In summary, a mild VPP method has been successfully developed for the synthesis of a PPy $/ \mathrm{V}_{2} \mathrm{O}_{5}$ composite film on the reactive metal $\mathrm{Mg}$. The microstructure of the composite film exhibits wire-like morphology with a diameter of about $40-50 \mathrm{~nm}$. FTIR and EDX tests confirmed that the film is a composite of PPy and $\mathrm{V}_{2} \mathrm{O}_{5}$, with conductivity in the range of $0.20-1.22 \mathrm{~S} / \mathrm{cm}$. The TGA tests showed that the composites synthesized at different temperatures (room temperature, $60,120,180^{\circ} \mathrm{C}$ ) had a similar thermal stability and decomposition content. Electrochemical tests revealed that the corrosion resistance of bare $\mathrm{Mg}$ was improved due to the deposition of the composite films. Compared with the current existing VPP method for the formation of CPs, our method was a more convenient and cost-effective method because the VPP reaction could be carried out at room temperature under normal atmospheric pressure, and thus, there is no complex equipment required. Furthermore, the present mild method also could be applied to synthesize PPy-based composite film on the surface of reactive metal, which is impossible for the conventional VPP methods. These unique properties make the present mild VPP method very attractive for a variety of applications, such as the synthesis of CP-based composites and corrosion protection of the reactive metal.

Author Contributions: J.L., W.S. and D.G. designed the experiments and wrote the manuscript. J.L., Y.H., Y.S., X.Z. performed the experiments. Y.H., W.S. and D.G. offered valuable discussions in analyses and revised the manuscript. All authors discussed the results and contributed to the final manuscript. All authors have read and agreed to the published version of the manuscript.

Funding: This work was supported by the National Nature Science Foundation of China (31870986), the National Nature Science Foundation of China $(31271009,81271689)$, the Fundamental Research Funds for the Central Universities (2011121001), the Natural Science Foundation of Fujian Province (2011J01331), the Program for New Century Excellent Talents in University, and the Program for New Century Excellent Talents in Fujian Province University. The authors would like to thank Chenxi Shuai and Yuan Jiang for their kind assistance on the synthesis of $\mathrm{V}_{2} \mathrm{O}_{5}$ hydrogel.

Conflicts of Interest: The authors declare no conflict of interest.

\section{References}

1. Turhan, M.C.; Weiser, M.; Jha, H.; Virtanen, S. Optimization of electrochemical polymerization parameters of polypyrrole on Mg-Al alloy (AZ91D) electrodes and corrosion performance. Electrochim. Acta 2011, 56, 5347-5354. [CrossRef] 
2. Srinivasan, A.; Ranjani, P.; Rajendran, N. Electrochemical polymerization of pyrrole over AZ31 Mg alloy for biomedical applications. Electrochim. Acta 2013, 88, 310-321. [CrossRef]

3. Truong, V.T.; Lai, P.K.; Moore, B.T.; Muscat, R.F.; Russo, M.S. Corrosion protection of magnesium by electroactive polypyrrole/paint coatings. Synthetic Met. 2000, 110, 7-15. [CrossRef]

4. Bazzaoui, M.; Martins, J.I.; Bazzaoui, E.A.; Albourine, A. Environmentally friendly process for nickel electroplating of ABS. Appl. Surf. Sci. 2012, 258, 7968-7975. [CrossRef]

5. Ishizaki, T.; Hieda, J.; Saito, N.; Saito, N.; Takai, O. Corrosion resistance and chemical stability of super-hydrophobic film deposited on magnesium alloy AZ31 by microwave plasma-enhanced chemical vapor deposition. Electrochim. Acta 2010, 55, 7094-7101. [CrossRef]

6. Li, G.L.; Schenderlein, M.; Men, Y.J.; Mohwald, H.; Shchukin, D.G. Monodisperse Polymeric Core-Shell Nanocontainers for Organic Self-Healing Anticorrosion Coatings. Adv. Mater. Interfaces 2014, 1, 130019. [CrossRef]

7. Sarkar, S.; Sarswat, P.K.; Free, M.L. Metal oxides and novel metallates coated stable engineered steel for corrosion resistance applications. Appl. Surf. Sci. 2018, 456, 328-341. [CrossRef]

8. Zhu, G.Y.; Cui, X.K.; Zhang, Y.; Chen, S.G.; Dong, M.Y.; Liu, H.; Shao, Q.; Ding, T.; Wu, S.D.; Guo, Z.H. Poly (vinyl butyral)/Graphene oxide/poly (methylhydrosiloxane) nanocomposite coating for improved aluminum alloy anticorrosion. Polymer 2019, 172, 415-422. [CrossRef]

9. Nezakati, T.; Seifalian, A.; Tan, A.; Seifalian, A.M. Conductive Polymers: Opportunities and Challenges in Biomedical Applications. Chem. Rev. 2018, 118, 6766-6843. [CrossRef]

10. Zhao, F.; Shi, Y.; Pan, L.J.; Yu, G.H. Multifunctional Nanostructured Conductive Polymer Gels: Synthesis, Properties, and Applications. Acc. Chem. Res. 2017, 50, 1734-1743. [CrossRef]

11. Kayser, L.V.; Lipomi, D.J. Stretchable Conductive Polymers and Composites Based on PEDOT and PEDOT:PSS. Adv. Mater. 2019, 31, 1806133. [CrossRef]

12. Liu, H.; Li, Q.M.; Zhang, S.D.; Yin, R.; Liu, X.H.; He, Y.X.; Dai, K.; Shan, C.X.; Guo, J.; Liu, C.T.; et al. Electrically conductive polymer composites for smart flexible strain sensors: A critical review. J. Mater. Chem. C 2018, 6, 12121-12141. [CrossRef]

13. Gharahcheshmeh, M.H.; Gleason, K.K. Device Fabrication Based on Oxidative Chemical Vapor Deposition (oCVD) Synthesis of Conducting Polymers and Related Conjugated Organic Materials. Adv. Mater. Interfaces 2019, 6, 1801564. [CrossRef]

14. Cacialli, F.; Bruschi, P. Site-selective chemical-vapor-deposition of submicron-wide conducting polypyrrole films: Morphological investigations with the scanning electron and the atomic force microscope. J. Appl. Phys. 1996, 80, 70-75. [CrossRef]

15. Cho, J.; Shin, K.H.; Jang, J. Polyaniline micropattern onto flexible substrate by vapor deposition polymerization-mediated inkjet printing. Thin Solid Films 2010, 518, 5066-5070. [CrossRef]

16. Dall'Acqua, L.; Tonin, C.; Varesano, A.; Canetti, M.; Porzio, W.; Catellani, M. Vapour phase polymerisation of pyrrole on cellulose-based textile substrates. Synthetic Met. 2006, 156, 379-386. [CrossRef]

17. Shin, K.H.; Cho, J.; Jang, J.; Jang, H.S.; Park, E.S.; Song, K.; Kim, S.H. Polypyrrole top-contact electrodes patterned by inkjet printing assisted vapor deposition polymerization in flexible organic thin-film transistors. Org. Electron. 2012, 13, 715-720. [CrossRef]

18. Bhattacharyya, D.; Howden, R.M.; Borrelli, D.C.; Gleason, K.K. Vapor phase oxidative synthesis of conjugated polymers and applications. J. Polym. Sci. 2012, 50, 1329-1351. [CrossRef]

19. Robinson, M.T.; Simons, C.E.; Cliffel, D.E.; Jennings, G.K. Photocatalytic photosystem I/PEDOT composite films prepared by vapor-phase polymerization. Nanoscale 2017, 9, 6158-6166. [CrossRef]

20. Yasin, M.N.; Brooke, R.K.; Rudd, S.; Chan, A.; Chen, W.T.; Waterhouse, G.I.N.; Evans, D.; Rupenthal, I.D.; Svirskis, D. 3-Dimensionally ordered macroporous PEDOT ion-exchange resins prepared by vapor phase polymerization for triggered drug delivery: Fabrication and characterization. Electrochim. Acta 2018, 269, 560-570. [CrossRef]

21. Zuber, K.; Shere, H.; Rehmen, J.; Wheaton, V.; Fabretto, M.; Murphy, P.J.; Evans, D.R. Influence of Postsynthesis Heat Treatment on Vapor-Phase-Polymerized Conductive Polymers. Acs Omega 2018, 3, 12679-12687. [CrossRef] [PubMed]

22. Xiong, C.R.; Aliev, A.E.; Gnade, B.; Balkus, K.J. Fabrication of silver vanadium oxide and $\mathrm{V}_{2} \mathrm{O}_{5}$ nanowires for electrochromics. Acs Nano 2008, 2, 293-301. [CrossRef] [PubMed] 
23. Malook, K.; Khan, H.; Shah, M. Synthesis, characterization and electrical properties of polypyrrole/ $\mathrm{V}_{2} \mathrm{O}_{5}$ composites. Korean J. Chem. Eng. 2018, 35, 12-19. [CrossRef]

24. Perera, S.D.; Patel, B.; Nijem, N.; Roodenko, K.; Seitz, O.; Ferraris, J.P.; Chabal, Y.J.; Balkus, K.J. Vanadium Oxide Nanowire-Carbon Nanotube Binder-Free Flexible Electrodes for Supercapacitors. Adv. Energy Mater. 2011, 1, 936-945. [CrossRef]

25. Zia, J.; Kashyap, J.; Riaz, U. Facile synthesis of polypyrrole encapsulated $\mathrm{V}_{2} \mathrm{O}_{5}$ nanohybrids for visible light driven green sonophotocatalytic degradation of antibiotics. J. Mol. Liq. 2018, 272, 834-850. [CrossRef]

26. Bai, M.H.; Bian, L.J.; Song, Y.; Liu, X.X. Electrochemical Codeposition of Vanadium Oxide and Polypyrrole for High-Performance Supercapacitor with High Working Voltage. Acs Appl. Mater. Interfaces 2014, 6, 12656-12664. [CrossRef]

27. Jadhav, N.; Jensen, M.B.; Gelling, V. Tungstate and vanadate-doped polypyrrole/aluminum flake composite coatings for the corrosion protection of aluminum 2024-T3. J. Coat. Technol. Res. 2015, 12, 259-276. [CrossRef]

28. Ren, X.Z.; Shi, C.; Zhang, P.X.; Jiang, Y.K.; Liu, J.H.; Zhang, Q.L. An investigation of $\mathrm{V}_{2} \mathrm{O}_{5} /$ polypyrrole composite cathode materials for lithium-ion batteries synthesized by sol-gel. Mater. Sci. Eng. B Adv. 2012, 177, 929-934. [CrossRef]

29. Kim, Y.T.; Kim, W.S.; Rhee, H.W.; Song, M.K. Iron corrosion protection by ultra-thin conductive films based on polypyrrole/poly(methyl methacrylate) composite. Mol. Cryst. Liq. Cryst. 2006, 445, 193-200. [CrossRef]

30. Li, F.; Li, G.X.; Zeng, J.; Gao, G.H. Molybdate-Doped Copolymer Coatings for Corrosion Prevention of Stainless Steel. J. Appl. Polym. Sci. 2014, 131, 40602. [CrossRef]

31. Song, S.; Song, G.L.; Shen, W.; Liu, M. Corrosion and Electrochemical Evaluation of Coated Magnesium Alloys. Corrosion 2012, 68. [CrossRef]

(C) 2020 by the authors. Licensee MDPI, Basel, Switzerland. This article is an open access article distributed under the terms and conditions of the Creative Commons Attribution (CC BY) license (http://creativecommons.org/licenses/by/4.0/). 